1 Mold JW, Stein HF. The cascade effect in the clinical care of patients. $N$ Engl $\mathcal{J}$ Med 1986;314:512-4

2 Dyken M, Pokras R. The performance of endarterectomy for disease of the extracranial arteries of the head. Stroke 1984;15:948-50.

3 Brott TG, Labutta CPT, Kempcinski RF. Changing patterns of carotid endarterectomy in a large metropolitan area. JAMA 1986;255:2609-12.

4 Heyman A, Wilkinson WE, Heyden S, et al. Risk of stroke in patients with cervical arterial bruits. N Eingl Y Med 1980;302:838-41.

5 Wolf PA, Kannel WB, Sorlie P, MCNamara P. Asymptomatic carotid bruit and the risk of stroke. The Framingham study. FAMA 1981;245:1442-5.

6 Chambers B, Norris JW. Outcome in patients with asymptomatic neck bruits. $N$ Engl $\mathcal{J}$ Med $1986 ; 315: 860-5$

7 Autret A, Pourcelot L, Saudeau D, Marchal C, Bertrand PH, De Boisvilliers S. Stroke risks in patients with carotid stenosis. Lancet 1987; i:888-90.

8 Hennerici M, Rautenberg W. Therapy of ischaemic cerebrovascular disease. $N$ Engl J Med 1984;311:1124.

9 Jacobs NM, Grant EG, Schellinger D, Cohan SL, Byrd CM. The role of duplex carotid sonography, digital subtraction angiography and arteriography in the evaluation of transient ischaemic attack and the asvmptomatic carotid bruit. Med Clin North Am 1984;68:1423-50.

10 Steiner TJ, McIvor J, Perkin GD, Greenhalgh RM, Rose FC. Morbidity of arch and carotid angiography: prospective survey. In: Greenhalgh RM, Rose FC, eds. Progress in stroke research 2. London: Pitman Medical, 1983:136-53.

11 Chambers BR, Norris JW. The case against surgery for asymptomatic carotid stenosis. Stroke 1984;15:964-7.

12 Fields WS, Maslenikov V, Meyer JS, Hass WK, Remington RD, MacDonald M. Joint study of extracranial arterial occlusion. V Progress report of prognosis following surgical or non-surgical treatment for transient ischacmic attacks and cervical carotid artery lesions. FAMA 1970;211: 1993-2003.

13 Shaw DA, Venables GS, Cartlidge NEF, Bates D, Dickinson PH. Carotid endarterectomy in patients with transient cerebral ischaemia. 7 Neurol $S_{c i} 1984 ; 64: 45-53$.

14 Ropper AH, Wechsler LR, Wilson LS. Carotid bruit and the risk of surgery. $N$ Engl 7 Med 1982;307:1388-90

15 Toronto cerebrovascular study group. Risks of carotid endarterectomy. Stroke 1986;17: $848-52$.

\section{Diagnosing pulmonary thromboembolism}

About a third of patients with untreated symptomatic pulmonary embolism die, ${ }^{1-3}$ but with treatment the mortality is only $8 \% .^{45}$ Nevertheless, pulmonary embolism is diagnosed in only $29 \%$ of episodes, ${ }^{6}$ mostly because of the varied manifestations. What are the manifestations and how can we improve our diagnostic rates?

The classic triad is dyspnoea, pleural pain, and haemoptysis, but these occur in only a fifth of the patients with major pulmonary embolism. ' Pulmonary embolism affects the circulation and these effects may be misdiagnosed as being due to heart disease. ${ }^{8}$ Thromboembolism often causes a mild fever but occasionally is associated with a very high temperature leading to diagnostic confusion. ${ }^{+}$Mild fever, diaphragmatic pleurisy, and an increased serum bilirubin concentration may also give rise to confusion since these may be due to cholecystitis. Again, pulmonary embolism may cause pulmonary oedema, ${ }^{8}$ bronchospasm, ${ }^{9}$ alveolar collapse, pulmonary infarction, and pleural effusions and therefore lead the doctor to misdiagnose asthma, bronchitis, or pneumonia.

Similar confusion may arise from the results of investigations, which again give non-specific results. In several large series of patients with a clinical diagnosis of pulmonary embolism and an abnormal isotope perfusion scan pulmonary arteriography showed that only $17-50 \%$ had pulmonary embolism. ${ }^{4111}$ Pulmonary arteriography is the gold standard for diagnosing pulmonary embolism; it is safe,,$^{12}$ accurate,${ }^{1314}$ and reproducible, with close agreement in the interpretation of the results between independent observers. ${ }^{12}$ Nevertheless, this investigation is much underused, and the first special procedure a doctor is likely to ask for is an isotope perfusion scan. The results of chest radiography, electrocardiogram, and measurement of the partial pressure of the arterial blood gases are of no diagnostic value. ${ }^{10}$
Abnormalities of isotope perfusion scans may be due to many lesions, of which pulmonary embolism is one, but abnormalities indistinguishable from those due to pulmonary embolism occur in 5\% of normal healthy volunteers. ${ }^{\text {is }}$ An abnormal result of an isotope perfusion scan demands further investigation, although a normal result virtually excludes the possibility of pulmonary embolism. ${ }^{1017}$ Many workers believe that an isotope scan showing normal ventilation in the area of diminished perfusion is diagnostic of pulmonary embolism. This is true only if the perfusion defect is segmental or larger." 16 With smaller defects the probability of pulmonary emboli being present is only $18-63 \% .{ }^{116}$ Other conditions clearly cause mismatching of ventilation and perfusion $(\mathrm{V} / \mathrm{Q}) .^{18}$

The presence of similar abnormalities of both ventilation and perfusion is often taken as indicating a disorder other than pulmonary embolism. Nevertheless, pulmonary emboli affect ventilation ${ }^{10}$ and hence may give rise to matched ventilation and perfusion defects. No fewer than a third of patients with matched ventilation and perfusion defects shown on isotope scans have pulmonary emboli. Unfortunately many clinicians rely almost entirely on this technique in diagnosing pulmonary embolism, ${ }^{19}$ and the resultant total error (false positives and false negatives) is unacceptable at $21 \% .^{16}$

In the few patients who are too ill for pulmonary arteriography ascending phlebography should be considered. The presence of venous thrombosis suggests that cardiorespiratory symptoms are due to pulmonary embolism, but a third of patients with pulmonary embolism have no evidence of this."

My scheme for diagnosing pulmonary embolism is in four parts. Firstly, consider the possibility of pulmonary embolism in all cases. Secondly, perform an isotope perfusion scan. If the result is normal dismiss the diagnosis of pulmonary embolism unless the clinical suspicion is overwhelming. If this shows segmental or larger defects then an isotope ventilation scan is indicated. If the abnormally perfused area shows normal ventilation then the diagnosis of pulmonary embolism is accepted unless surgery or thrombolytic treatment is contemplated. Lastly, in all other circumstances pulmonary arteriography is indicated, with particular attention being paid to the abnormal areas shown on the perfusion scan.

W J WINDEBANK

Consultant Physician,

Derbyshire Royal Infirmary,

Derby DE1 2QY

1 Barratt DW, Jordan SC. Anticoagulant drugs in treatment of pulmonary embolism: controlled trial. Lancet 1960;i:1309-12.

2 Coon WW, Willis PW, Symous MJ. Assessment of anticoagulant treatment of venou thromboembolism. Am Surg 1969;170:559-67.

3 Hermann RE, Davis JW, Holden WD. Pulmonary embolism: a clinical and pathological studv with emphasis on the effects of prophylactic therapy with anticoagulants. Am f Surs 1961;102:19-28.

4 Sassahara AA, Hyers TM, Cole CM, et al, eds. The urokinase pulmonary embolism trial. Circulation 1973;47(suppl): 1-108.

5 Alpert JS, Dalen JE. Unpublished data quoted in: Sassahara AA, Saneblick EH, Lesch M Pulmonary emboli. New York: Grune and Stratton, 1975:80-1.

6 Dalen JE, Alpert JW. Natural history of pulmonary embolism. Prog Cardiovasc Dis 1975;17 259-69.

7 Wenger NK, Stein PD, Willis PW. Massive acute pulmonary embolism. The deceivingly non-specific manifestations. FAMA 1972;220:843-4.

8 Windebank WJ, Boyd G, Moran F. Pulmonary thrombo-embolism presenting on cardiac emergencies. Scott Med J 1974;19:221-8.

9 Windebank WJ, Boyd G, Moran F. Pulmonary embolism presenting as asthma. $\mathrm{Br}$ Med $\mathcal{I}$ 1973;i:90-4.

10 Robin ED. Over diagnosis and over treatment of pulmonary embolism: the emperor may have no clothes. Ann Intern Med 1977;87:775-81.

11 Hull RD, Raskob GE, Hirsh J. The diagnosis of clinically suspected pulmonary embolism: practical approaches. Chest 1986;89(suppl):417-25

12 Bell WR, Simon TL. A comparative analysis of pulmonary perfusion scans with pulmonary angiograms. From a national co-operative study. Am Heart f 1976;92:700-6. 
13 Novelline RA, Baltarovich $\mathrm{OH}$, Athanasoulis CA, et al. The clinical course of patients with suspected pulmonary embolism and a negative arteriogram. Radiology 1978;126:561-7.

14 Dalen JE, Brooks HL, Johnson LW, et al. Pulmonary angiography in acute pulmonary embolism: indications, techniques and results in 367 patients. Am Heart f 1971;81:175-85.

15 Tentalman MR, Hoffer PB, Heck LL, Kunzmann A, Gottschalk A. Perfusion scans in normal volunteers. Radiology 1973:106:593-4.

16 McBride K, La Morte WW, Menzoian JO. Can ventilation-perfusion scans accurately diagnose acute pulmonary embolism? Arch Surg 1986;121:754-7.

17 (iutnk LM. Pulmonary embolus with a normal ventilation prrfusion lung scan. $S$ D g Mid 1983;36:17-9.

18 McNeil BJ. A diagnostic strategy using ventilation-perfusion studies in patients suspect for pulmonary embolism. F Nucl Med 1976;17:613-6.

19 Frankez N, Coleman RE, Pryor DB, Sostman HD, Ravin CE. Utilisation of lung scans by clinicians. f Nucl Med 1986;27:366-9.

\section{Child abuse or copper deficiency? A radiological view}

Copper deficiency has been a recognised cause of hypochromic, microcytic anaemia and neutropenia in infants for

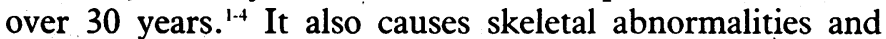
fractures, and recently copper deficiency has been offered to the courts (and given wide publicity) as an explanation of the radiological findings in children whose parents have been charged with abuse. The case of one such child with multiple rib, long bone, and metaphysical fractures was recently heard by the Court of Appeal. In dismissing the appeal the Lord Chief Justice rejected the defence's evidence on copper deficiency and suggested that it actually strengthened the prosecution case.

Should copper deficiency be considered in the differential diagnosis of non-accidental injury? The skeletal manifestations of copper deficiency occur late ${ }^{+}$and comprise retardation of bone age, osteoporosis (which is often severe), metaphyseal cupping, increased density of the zone of provisional calcification, and metaphyseal sickle shaped spurs. These changes are distributed symmetrically throughout the skeleton. ${ }^{5}$ Copper deficiency is rare-only about 100 cases have been reported-and fractures caused by copper deficiency are even rarer: there have been 16 documented cases, and only five in term infants. ${ }^{35-7}$ Full term infants are born with high body stores of copper that are sufficient for at least the first six months of life. Modern British infant feeding formulas containing $40 \mu \mathrm{g}$ copper per $100 \mathrm{ml}$ are not associated with copper deficiency in term infants, and no breast fed infant has ever developed copper deficiency. The five full term infants with fractures were all having an abnormal diet or total parenteral nutrition. Rib fractures have been recorded only in premature infants, and skull fractures have never been described. All the children with fractures had obviously abnormal bones.

Metaphyseal fractures are highly suggestive of nonaccidental injury and are the most valuable single diagnostic radiographic feature. ${ }^{8}$ They are undoubtedly traumatic: some parents admit to injuring their child, and similar lesions are seen in newborn infants who have suffered a traumatic breech delivery. The new bone formation that accompanies fracture healing is often not present with intra-articular fractures, ${ }^{9}$ and the fractures themselves often do not produce local pain, swelling, and heat. ${ }^{810}$ Those who are unfamiliar with this picture may discount a traumatic origin and ascribe the radiological signs to another cause of metaphyseal abnormalities-such as copper deficiency.

The differentiation of metaphyseal abnormalities caused by copper deficiency from metaphyseal fractures caused by child abuse and from normal developmental variants, such as cupping of the anterior ends of ribs and metaphyseal breaking, is not difficult for the experienced. BennaniSmires $e t a l^{7}$ described a term infant with multiple metaphyseal fractures caused by copper deficiency that mimicked non-accidental injury, pointing out that it might be possible to confuse the two conditions. The fractures were, however, symmetrical, and other signs of copper deficiency-that is, osteoporosis, metaphyseal cupping, and sickle shaped spurs -were also present. The presence of otherwise normal bones with a normal bone age excludes copper deficiency of a severity sufficient to cause fractures. When other features of copper deficiency (low serum copper and caeruloplasmin concentrations, neutropenia, and anaemia) and predisposing factors (prematurity, total parenteral nutrition, or copper deficient milk) are also absent we can be even more confident.

STEPHEN CHAPMAN

Consultant Paediatric Radiologist,

Children's Hospital

Birmingham B16 8ET

Sturgeon P, Brubaker C. Copper deficiency in infants. Am f Dis Child 1956:92:254-65.

2 Schubert WK Lahey ME Copper and protein depetion complicating hypoferric anaemia of infancy. Pediatrics 1959;24:710-33.

3 Cordano A, Baertl JM, Graham GG. Copper deficiency in infancy. Pediatrics 1964:34:324-36.

4 Graham GG, Cordano A. Copper depletion and deficiency in the malnourished infant. Fohns Hopkins Med F 1969;124:139-50.

5 Grünebaum $M$, Horodniceanu $C$, Steinherz R. The radiographic manifestations of bone changes in copper deficiency. Pediatr Radiol 1980;9:101-4.

6 Cordano A, Graham GG. Copper deficiency complicating severe chronic intestinal malabsorption. Pediatrics 1966;38:596-604.

7 Bennani-Smires C, Medina J, Young LW. Infantile nutritional copper deficiency. Am 7 Dis Child 1980;134:1155-6.

8 Caffev J. The first annual Neuhauser presidential address of the Society for Paediatric Radiology. The parent-infant stress syndrome (Caffey-Kempe syndrome), (battered babe syndrome Am 7 Roentgenol 1977;114:217-29.

9 Cameron JM, Rae LJ. Atlas of the battered child syndrome. Edinburgh: Churchill Livingstone, 1975:34.

10 Merten DF, Radkowski MA, Leonidas JC. The abused child: a radiological reappraisal. Radiologv 1983;146:377-81

\section{Assessment before prostatectomy}

Prostatectomy is best performed by the transurethral method. Since most patients will be over 60 preoperative cardiopulmonary assessment is required, and in some cases spinal rather than general anaesthesia may be essential. Preoperative intravenous urography used to be performed routinely, but this policy has been questioned. ${ }^{1}$ Plain abdominal radiography and ultrasonography may give the same information more easily and cheaply. ${ }^{2}$ Others have concluded, however, that preprostatectomy urography "remains a sound principle of good urological care." 3

Urography may show an intravesical prostatic impression, but prostatic size bears no relation to the symptoms or degree of bladder outlet obstruction. Prostatic size or malignant infiltration are in any case better shown by transrectal ultrasonography or computed tomography. ${ }^{45}$ Nor does the unmodified urogram give quantifiable data on total or split renal function; these require additional clearance studies and radionuclide techniques. ${ }^{67}$ Dilatation of the upper urinary tract in high pressure chronic retention or ureteric invasion by prostatic cancer will be apparent, but the former condition can be diagnosed on clinical criteria ${ }^{8}$ and the latter condition will be shown by histological examination. Showing dilatation preoperatively is unlikely to affect primary management. An empty bladder on urography does not exclude obstruction- 